\title{
Neurogenic Subventricular Zone Stem/Progenitor Cells Are Notch1-Dependent in Their Active But Not Quiescent State
}

\author{
Onur Basak, ${ }^{1 \star}$ Claudio Giachino, ${ }^{1,2 *}$ Emma Fiorini, ${ }^{3}$ H. Robson MacDonald, ${ }^{3}$ and Verdon Taylor ${ }^{1,2}$ \\ ${ }^{1}$ Department of Molecular Embryology, Max Planck Institute of Immunobiology and Epigenetics, D-79108 Freiburg, Germany, ${ }^{2}$ Embryology and Stem Cell \\ Biology, Department of Biomedicine, University of Basel, CH-4058 Basel, Switzerland, and ${ }^{3}$ Ludwig Center for Cancer Research, University of Lausanne, \\ CH-1066 Epalinges, Switzerland
}

\begin{abstract}
The adult mammalian forebrain contains neural stem/progenitor cells (NSCs) that generate neurons throughout life. As in other somatic stem cell systems, NSCs are proposed to be predominantly quiescent and proliferate only sporadically to produce more committed progeny. However, quiescence has recently been shown not to be an essential criterion for stem cells. It is not known whether NSCs show differences in molecular dependence based on their proliferation state. The subventricular zone (SVZ) of the adult mouse brain has a remarkable capacity for repair by activation of NSCs. The molecular interplay controlling adult NSCs during neurogenesis or regeneration is not clear but resolving these interactions is critical in order to understand brain homeostasis and repair. Using conditional genetics and fate mapping, we show that Notch signaling is essential for neurogenesis in the SVZ. By mosaic analysis, we uncovered a surprising difference in Notch dependence between active neurogenic and regenerative NSCs. While both active and regenerative NSCs depend upon canonical Notch signaling, Notch1-deletion results in a selective loss of active NSCs (aNSCs). In sharp contrast, quiescent NSCs (qNSCs) remain after Notch1 ablation until induced during regeneration or aging, whereupon they become Notch1-dependent and fail to fully reinstate neurogenesis. Our results suggest that Notch1 is a key component of the adult SVZ niche, promoting maintenance of aNSCs, and that this function is compensated in qNSCs. Therefore, we confirm the importance of Notch signaling for maintaining NSCs and neurogenesis in the adult SVZ and reveal that NSCs display a selective reliance on Notch1 that may be dictated by mitotic state.
\end{abstract}

\section{Introduction}

Continuous neurogenesis within the adult mammalian forebrain is spatially restricted to neural stem/progenitor cell (NSC)containing germinal niches with remarkable regenerative capacity (Reynolds and Weiss, 1992; Morshead et al., 1994; Doetsch et al., 1999a; Gage, 2000; Mirzadeh et al., 2008). Whereas the dentate gyrus generates granule neurons for the local hippocampal circuitry, the subventricular zone (SVZ) produces multiple interneuron types within the olfactory network. The cellular composition of the SVZ has been characterized in detail and specialized astrocytes are NSCs (Doetsch et al., 1999b; Johansson et al., 1999; Morshead et al., 2003; Coskun et al., 2008; Meletis et al., 2008; Carlén et al., 2009). SVZ NSCs are a heterogeneous cell population and their spatial distribution correlates with distinct cellular fates (Kohwi et al., 2007; Merkle et al., 2007; Young et al.,

\footnotetext{
Received Jan. 31, 2012; accepted Feb. 18, 2012.

Author contributions: V.T. designed research; O.B., C.G., and V.T. performed research; E.F., H.R.M., and V.T. contributed unpublished reagents/analytic tools; 0.B., C.G., and V.T. analyzed data; 0.B., C.G., and V.T. wrote the paper.

*0.B. and C.G. contributed equally to the work.

This work was supported by the Deutsche Forschungsgemeinschaft (SPP1109; TA-310-1; TA-310-2). 0.B. was a PhD student of the Faculty of Biology, University of Freiburg, Germany. We thank Dr. F. Radtke for the floxed Notch1 mice, Dr. T. Honjo for floxed RBP-J mice, and Dr. F. Guillemot for Ascl1 antibodies. We are grateful to Drs. M. Placzek and A. Furley for comments on the paper and to the members of the Taylor lab for helpful discussions and Frank Sager for excellent technical assistance.

Correspondence should be addressed to Dr. Verdon Taylor, Embryology and Stem Cell Biology, Department of Biomedicine, University of Basel, CH-4058 Basel, Switzerland. E-mail: verdon.taylor@unibas.ch.

DOI:10.1523/JNEUROSCI.0455-12.2012

Copyright $\odot 2012$ the authors $\quad 0270-6474 / 12 / 325654-13 \$ 15.00 / 0$
}

2007a). Active SVZ stem cells generate transient amplifying progenitors (TAPs) and subsequently newborn neurons (Merkle et al., 2007; Pastrana et al., 2009). Dormant NSCs are quiescent, resistant to antimitotic drugs, and contribute to regeneration. Feedback loops control SVZ neurogenesis and ablation of TAPs activates regenerative NSCs, which replenish the progenitor pools and reinstate neurogenesis (Doetsch et al., 1997, 1999a,b). In contrast, increased TAPs force NSCs into quiescence (Doetsch et al., 2002; Aguirre et al., 2010). It is currently unclear whether aNSCs and quiescent regenerative NSCs are different states of the same cell and thus share the same molecular signal requirements. Deciphering how NSCs are regulated is critical to understanding mammalian brain homeostasis and regeneration.

Multiple factors modulate neurogenesis, including Notch (Kuhn et al., 1997; Parras et al., 2004; Hack et al., 2005; Kohwi et al., 2005; Jackson et al., 2006; Ramírez-Castillejo et al., 2006; Balordi and Fishell, 2007; Young et al., 2007b; Colak et al., 2008; Basak and Taylor, 2009). Activated Notchs are cleaved to release the intracellular domain, which translocates to the nucleus to convert a CSL (RBP-J in mice) transcriptional repressor complex into an activator (Mumm and Kopan, 2000). Analyses of Notch signaling during adult neurogenesis have focused on global manipulation of the pathway with gamma-secretase inhibitors or by ablating RBP-J or have focused on the dentate gyrus. These experiments indicate that Notch signaling controls progenitor cell proliferation and neurogenesis in the dentate gyrus, as well as survival and self-renewal in the SVZ (Breunig et al., 2007; Ables et al., 2010; Aguirre et al., 2010; Chapouton et al., 2010; Ehm et al., 2010; 
Table 1. Primary and secondary antibodies used in the analysis

\begin{tabular}{llrl}
\hline Antigen & Species & Dilution, 1: & Source \\
\hline Notch1 (intracellular domain) & Rabbit & 1000 & Nyfeler et al., 2005 \\
Notch1 (extracelluar domain) & Rat & 100 & H. R. MacDonald \\
Notch2 (extracelluar domain) & Rat & 100 & H. R. MacDonald \\
Notch3 & Goat & 100 & R\&D Systems \\
bGal & Rabbit & 2000 & CAPPEL \\
PCNA & Mouse & 1000 & Dako North America \\
Doublecortin & Guinea pig & 2000 & Chemicon \\
Sox2 & Rabbit & 500 & Chemicon \\
BrdU & Rat & 2000 & Serotec \\
Ascl1 (Mash1) & Mouse & 200 & F. Guillemot \\
GFAP & Mouse & 500 & Sigma-Aldrich \\
Neuronal nuclear antigen (NeuN) & Mouse & 500 & Sigma \\
FITC/Cy3/Cy5 conjugated anti-mouse, & Donkey & 1000 & Jackson Immunoresearch \\
$\quad$ rabbit, rat, goat & & & \\
\end{tabular}

Lugert et al., 2010). However, these approaches caused extensive changes in the germinal zone and therefore could not take local niche and cellular feedback mechanisms into consideration. In addition, the specific roles of the individual Notch family members in the adult SVZ have not been examined in vivo. We conditionally inactivated Notch 1 by sparse genetic recombination, avoiding gross changes in morphology and cellular composition of the SVZ, to analyze the cell-autonomous role of Notch1. We provide evidence that Notch1 directly regulates neurogenesis by maintaining aNSCs and reveal a surprising distinct molecular requirement of NSCs for Notch1 that is dependent upon their activation state.

\section{Materials and Methods}

Animals, tamoxifen administration, and AraC treatment. Transgenic Nestin::creER $R^{T 2}$ mice, conditional Notch $1^{\text {lox }}$ mice, and Rosa26R mice have been described previously (Soriano, 1999; Han et al., 2002; Lütolf et al., 2002; Giachino and Taylor, 2009). Conditional Notch1 $1^{\text {lox/lox }}$ Nestin::creER $R^{T 2}$ Rosa26R (Notch1 cKO), Notch $1^{+/+}$Nestin::creER ${ }^{T 2}$ Rosa26R, and Notch $1^{+ \text {lox }}$ Nestin:: creER ${ }^{T 2}$ Rosa26R (control) animals of either sex were used for Notch1 loss-of-function experiments. RBP-J ${ }^{\text {lox } / l o x}::$ :creER $R^{T 2}$ Rosa26R (RBP-J cKO), RBP-J ${ }^{+/+}$Nestin::creER ${ }^{T 2}$ Rosa26R and $R B P-J^{+/ l o x}::$ creER $R^{T 2}$ Rosa26R (control) animals were used for RBP-J loss-of-function experiments. All animals were heterozygous for the Nestin:: $c r e E R^{T 2}$ transgene. Adult mice (8-10 weeks old) were injected intraperitoneally with a daily dose of $2 \mathrm{mg}$ of tamoxifen (TAM) for $10 \mathrm{~d}$ and killed 0,15 , or $45 \mathrm{~d}$, or 1 year after the end of the TAM treatment. Adult C57BL/6 mice were used for expression analysis. AraC infusion experiments were performed as described previously (Doetsch et al., 1999a). Mice were maintained in a $12 \mathrm{~h}$ day/night cycle with adequate food and water under specific pathogen-free conditions and according to Max Planck institutional and German federal regulations and under license numbers H-05/01, 0-06/02, G-09/18 and G-09/19.

Tissue preparation and immunostaining. Tissue preparation and X-Gal staining have been described previously (Giachino and Taylor, 2009). Sections of the adult brain were blocked at room temperature (RT) for $30 \mathrm{~min}$ with $2 \%$ normal donkey serum or $5 \%$ normal goat serum (Jackson Immunoresearch Laboratories) in $0.3 \%$ TritionX-100 in PBS, and incubated with the primary antibodies in the blocking solution at $4^{\circ} \mathrm{C}$ overnight. Sections were washed three times in PBS and incubated at RT for $2 \mathrm{~h}$ with the corresponding secondary antibodies and DAPI nuclear counterstained in blocking solution. Sections were embedded on glass slides in AF1 (Citifluor) or DABCO mounting media and visualized using a Zeiss LSM510 confocal microscope (Carl Zeiss). Sections were treated with $2 \mathrm{~N} \mathrm{HCl}$ at $37^{\circ} \mathrm{C}$ for 30 min for BrdU staining and with sodium citrate solution (10 mM, pH 7.4) at $80^{\circ} \mathrm{C}$ for $20 \mathrm{~min}$ for PCNA staining before the blocking step. Antibodies used in the experiments are described in Table 1.

$X$-Gal staining and quantification. For X-Gal staining, consecutive 20 $\mu \mathrm{m}$ thick sections were collected on glass slides and postfixed for $5 \mathrm{~min}$ with $2 \%$ PFA and $0.4 \%$ gluteraldehyde in PBS before staining with the X-Gal solution $\left(10 \mathrm{~mm} \mathrm{~K}_{3} \mathrm{Fe}(\mathrm{CN})_{6}, 10 \mathrm{~mm} \mathrm{~K}_{4} \mathrm{Fe}(\mathrm{CN})_{6}, 2 \mathrm{~mm} \mathrm{MgCl}_{2}\right.$, and
$1 \mathrm{mg} / \mathrm{ml} \mathrm{X}$-Gal) at $37^{\circ} \mathrm{C}$ overnight. Sections were counterstained with DAPI (1:1000) and embedded in DABCO mounting medium. The numbers of X-Gal-positive cells in rostral migratory stream (RMS), granule, and periglomerular cell layers were counted separately using at least four sections per animal. Areas of the counted regions were calculated using the ImageJ software $(\mathrm{NIH})$ and all the results were represented as number of cells per square millimeter.

Data analysis, quantification, and statistical analysis. For counting cells after immunohistochemistry, $20-40-\mu \mathrm{m}$-thick $3 \mathrm{D}$ reconstructions of 8-12 regions that spanned the whole anterior-posterior and dorsalventral axis of the SVZ were generated at $63 \times$ using an LSM510 confocal microscope (Carl Zeiss). Cell counting and image processing was performed using Imaris 5.0 (Bitplane) and Adobe Photoshop CS4 software (Adobe Systems). Statistical comparisons were conducted by two-tailed unpaired Student's $t$ test. Significance was established at $p<0.05$.

\section{Results}

\section{Notch1 is expressed throughout the neurogenic SVZ}

The cytoarchitecture of the mouse SVZ has been well documented (Fig. 1A). Notch1 is expressed by subependymal cells in the SVZ (Stump et al., 2002; Nyfeler et al., 2005) including Glial Fibrillary Acidic Protein-positive $\left(\mathrm{GFAP}^{+}\right)$astrocytes (Fig. $1 \mathrm{~B}-$ E). Some Notch $1^{+} \mathrm{GFAP}^{+}$astrocytes extended processes that contacted the ventricles, a morphological attribute of NSCs (Fig. $1 D)$. Notch1 was expressed by mitotically inactive [Proliferating Cell Nuclear Antigen-negative ( $\mathrm{PCNA}^{-}$)] cells, including SVZ astrocytes $\left(\mathrm{PCNA}^{-} \mathrm{GFAP}^{+}\right)$and by many mitotic cells $\left(\mathrm{PCNA}^{+}\right)$, including putative aNSCs $\left(\mathrm{PCNA}^{+} \mathrm{GFAP}^{+}\right), \mathrm{Ascl}^{+}$TAPs (Fig. $1 E, F)$, and early $\mathrm{Dcx}^{+}$neuroblasts (Fig. $1 G$ ) (Nyfeler et al., 2005; Givogri et al., 2006; Carlén et al., 2009). Therefore, Notch1 is expressed by SVZ progenitors at different stages of differentiation from NSCs to neuroblasts and astrocytes.

\section{A cell autonomous role for Notch1 in adult neurogenesis}

We analyzed Notch1 functions in Nestin-expressing SVZ progenitors by conditional gene inactivation using a Nestin::creER ${ }^{T 2}$ mouse line and TAM induction in adult mice (Giachino and Taylor, 2009). Nestin::creER ${ }^{T 2}$-expressing cells in the SVZ include Sox $2^{+}$cells but not TAPs, neuroblasts, or neurons, implicating them as putative NSCs (Giachino and Taylor, 2009). TAM induction protocols were selected that targeted neurogenic SVZ NSCs in a sparse, mosaic fashion $(\sim 10 \%)$, sparing the majority of SVZ cells (Fig. 2A) (Giachino and Taylor, 2009). This approach enabled a cell-autonomous analysis of gene function and lineage tracing by following the constitutive expression of $\beta$-Galactosidase (bGal) after Cre-mediated recombination of the Rosa26R allele. To address the function of Notch1 in the SVZ, we combined the Nestin::creER ${ }^{T 2}$, floxed Notch1, and Rosa26R alleles and induced gene ablation in adult mice (Fig. $2 A$ ). We compared the relative amounts of targeted $\left(\mathrm{bGal}^{+}\right)$to nontargeted cells $\left(\mathrm{bGal}^{-}\right)$within each SVZ cell population of Notch $1^{+/+}$Nestin::creER ${ }^{T 2}$ Rosa26R (hereafter referred to as control) and Notch $1^{\Delta / \Delta}$ Nestin:: $c r e E R^{T 2}$ Rosa26R (hereafter referred to as Notch1 cKO) at different time points after TAM induction.

Neuroblasts are the main product of SVZ NSCs and an effective reporter of active neurogenesis. Fifteen and $45 \mathrm{~d}$ after TAM induction, newly generated $\mathrm{bGal}^{+}$neuroblasts entering the proximal RMS were dramatically reduced in Notch 1 cKO compared with control mice, suggesting a persistent defect in neurogenesis ( $50 \%$ and $57 \%$ reduction at 15 and $45 \mathrm{~d}$, respectively; Fig. $2 B-F$ ). In addition, fewer newly generated $\mathrm{bGal}^{+} \mathrm{NeuN}^{+}$neurons were present in the olfactory bulb $(\mathrm{OB})$ of Notch $1 \mathrm{cKO}$ compared with control mice (Fig. 2G-N). This included a significant reduction 

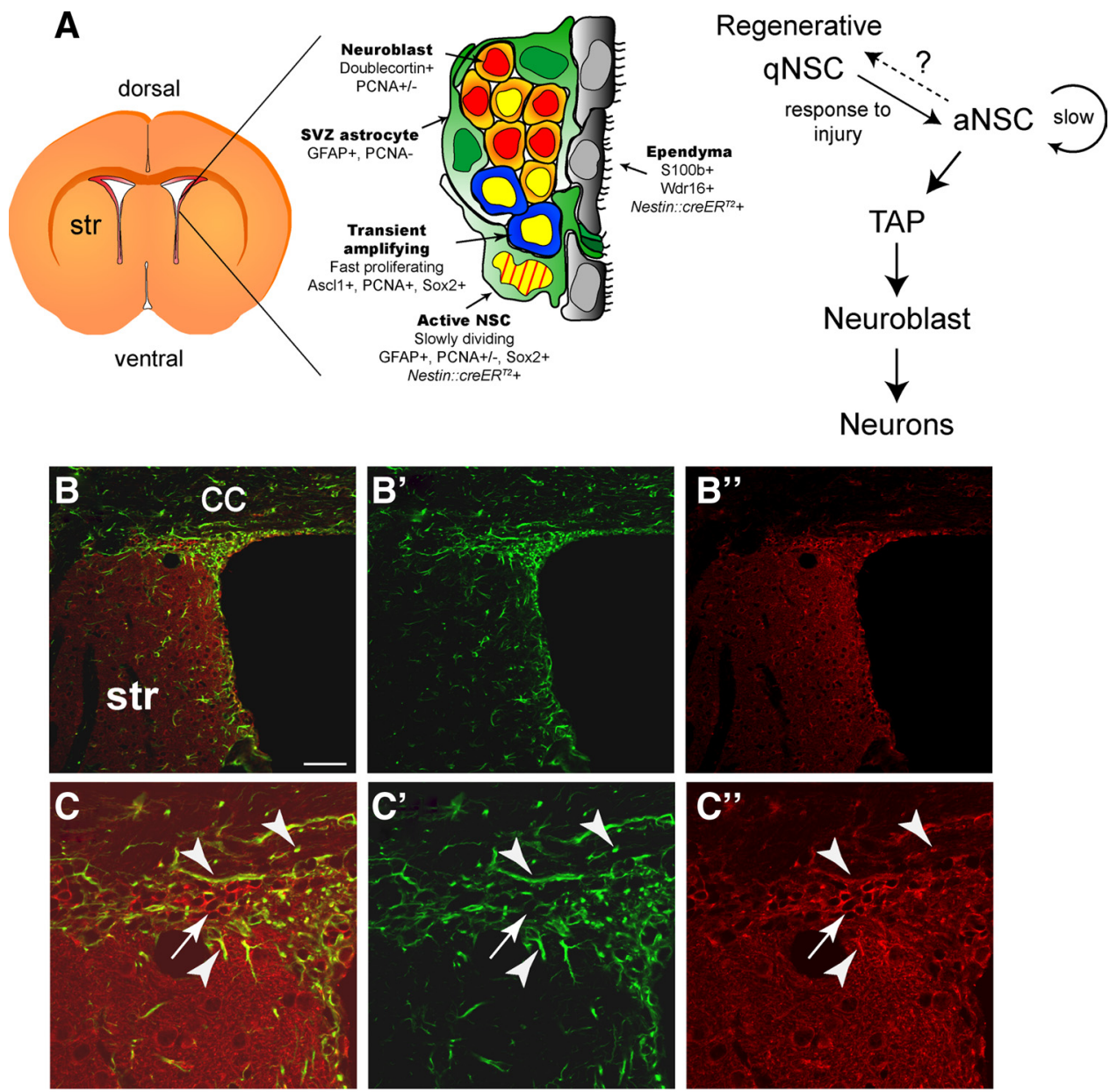

Notch1 GFAP
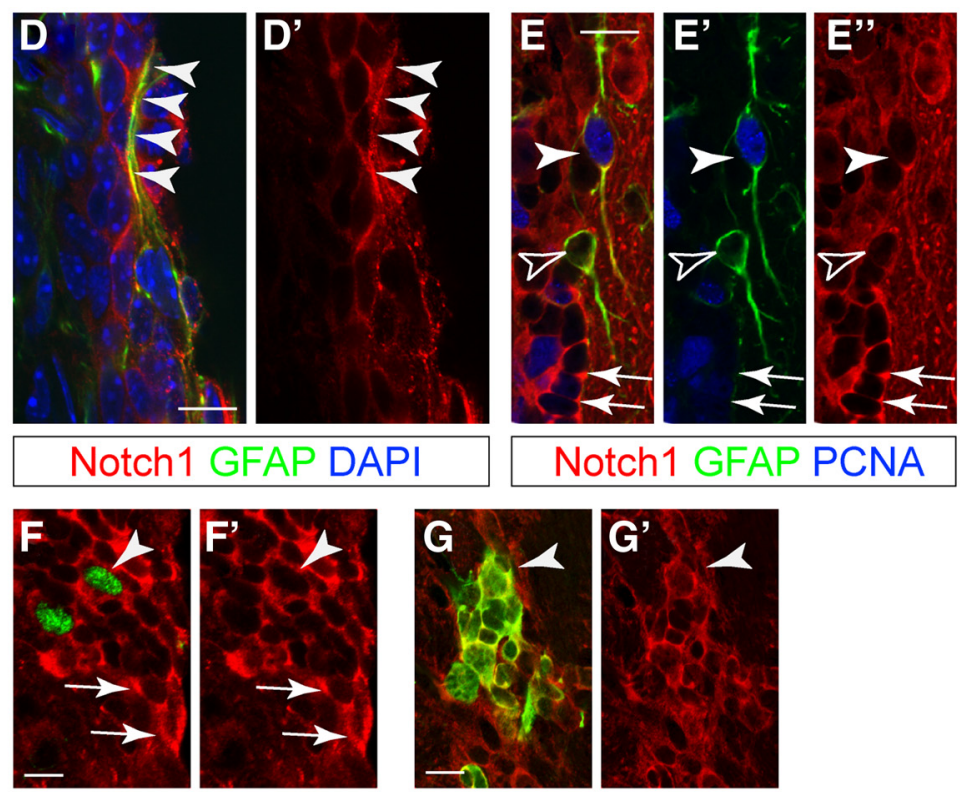

Notch1 Ascl1
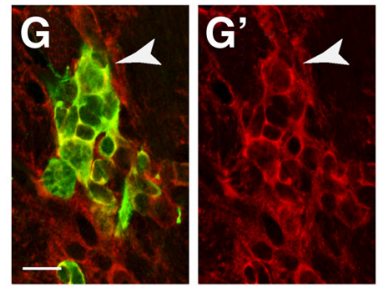

Notch1 Dcx

Figure 1. Notch1 is expressed in the adult subventricular zone niche. A, Schematic view of the SVZ and cell-type specific marker expression (adapted from Doetsch et al., 1999b). Hierarchical organization of the cells involved in adult neurogenesis in the SVZ. aNSC divide infrequently and generate TAPs, which in turn generate neuroblasts. Quiescent regenerative NSCs respond to signals (including injury), enter the cell cycle, and generate neurogenic aNSCs. It is unclear whether aNSC and regenerative qNSCs are independent states of the same cell and whether NSCs can shuttle between the two. Striped yellow nucleus is slow dividing, BrdU-retaining NSC; yellow nucleus is mitotically active cell. B, Low-magnification, confocal optical sections showing overview images of the lateral wall of the forebrain ventricle, including the SVZ. C, Notch1 protein codistributes with GFAP (arrowheads) but is also expressed by GFAP ${ }^{-}$cells (arrow). Higher-magnification images of sections in B.D, GFAP ${ }^{+}$SVZ astrocytes express Notch1, including putative NSCs, with processes contacting the lateral ventricle (arrowheads) and (Figurelegend continues.) 

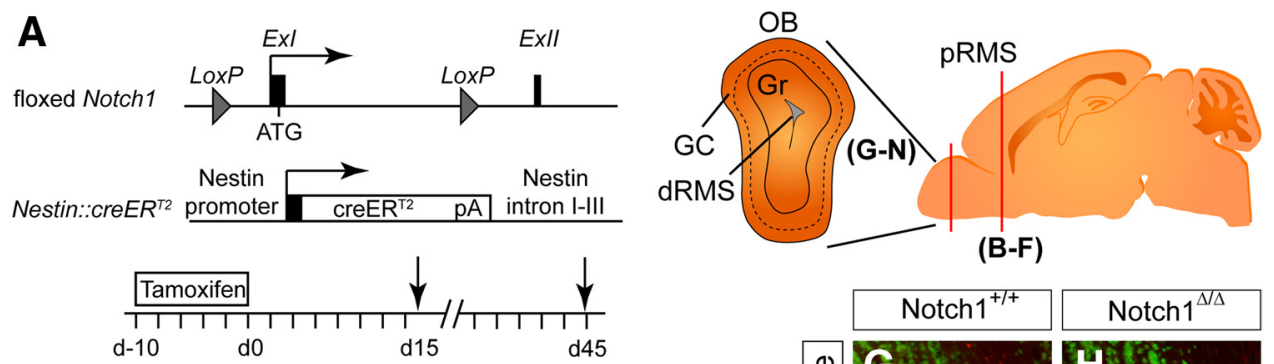

(B-F)

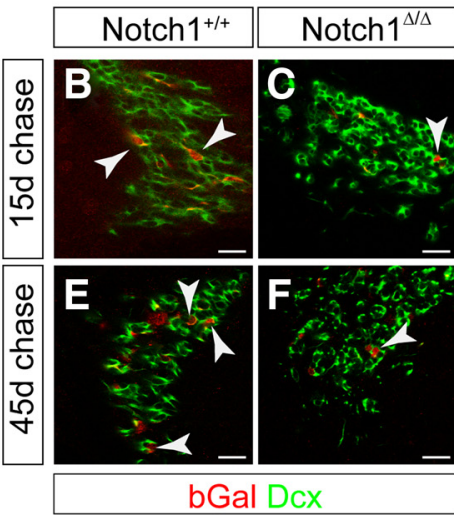

D
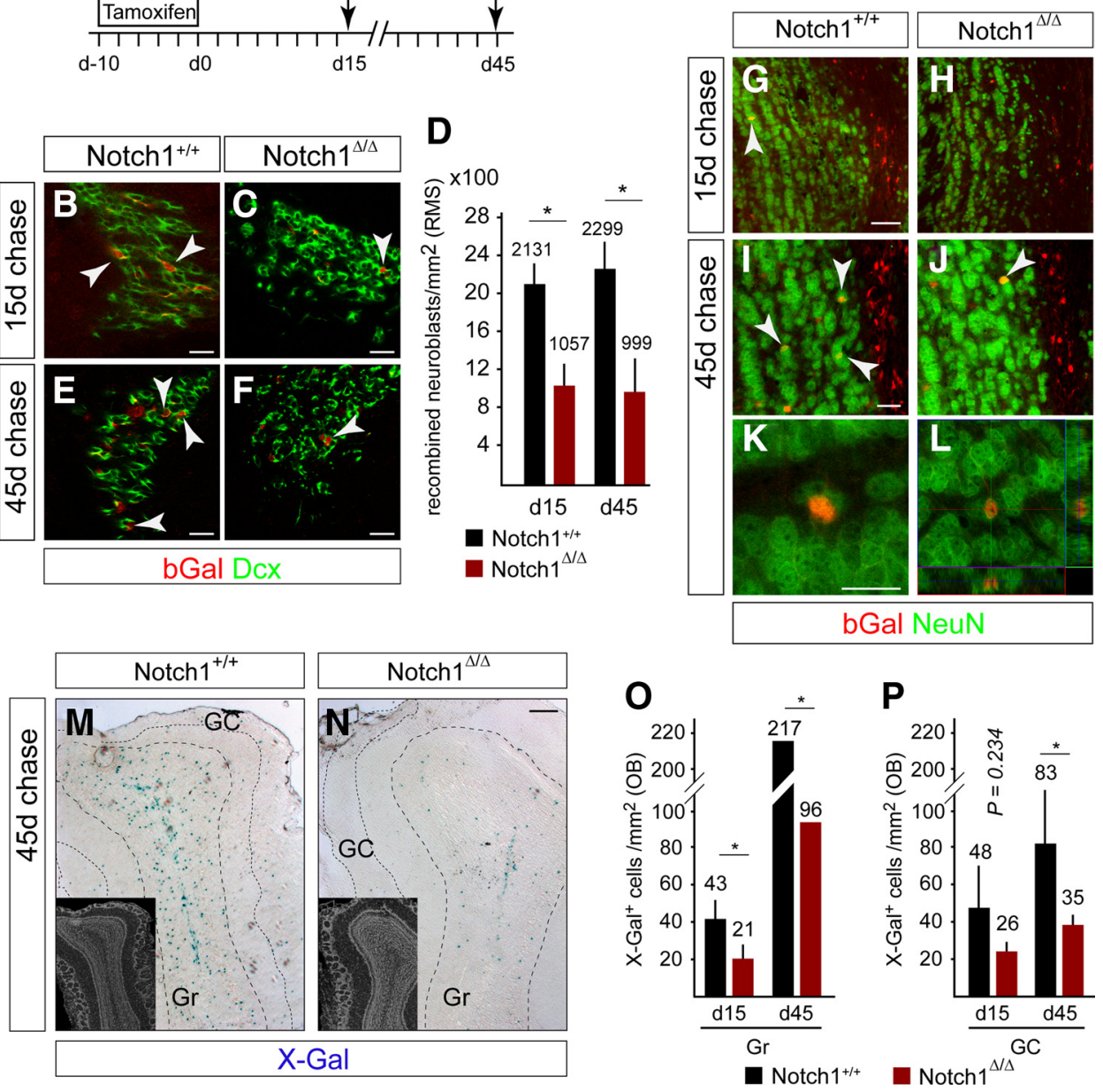

Figure 2. Notch1 ablation reduces the number of neuroblasts in the RMS and the number of newborn neurons in all OB layers. $A$, Scheme of the floxed Notch 1 locus (Exon I flanked with LoxP sites) and Nestin::creER ${ }^{T 2}$ alleles used in the analysis (Giachino and Taylor, 2009). Adult mice were induced with TAM for $10 \mathrm{~d}$, followed by a 15 or $45 \mathrm{~d}$ chase (death, arrow). Brains were analyzed on coronal sections at the level of the red bar (OB and proximal RMS). Schematicview of the OB showing the distal RMS (dRMS), granule cell (Gr) and glomerular cell layers (GC). B, $C$, bGal ${ }^{+}$Dcx ${ }^{+}$neuroblasts (arrowheads) in the proximal RMS (pRMS) are reduced in Notch 1 cKO (Notch ${ }^{\Delta / \Delta}$ ) compared with control (Notch1 ${ }^{+/+}$) animals 15 dafter TAM treatment. D, Quantification of bGal ${ }^{+}$neuroblasts in the RMS of Notch $1 \mathrm{cKO}$ (Notch $1^{\Delta / \Delta} ; n=$ 3) and control (Notch $1^{+/+} ; n=4$ ) animals 15 and $45 \mathrm{~d}$ after TAM treatment. The production of bGal ${ }^{+}$neuroblasts is reduced by day 15 and does not recover in Notch1 cKO animals. $E, F$, bGal ${ }^{+} \mathrm{Dcx}{ }^{+}$ neuroblasts (arrowheads) in the posterior RMS are reduced in Notch $1 \mathrm{CKO}$ (Notch $1^{\Delta / \Delta}$ ) compared with control (Notch $1^{+/+}$) animals $45 \mathrm{~d}$ after TAM treatment. G-L, bGal ${ }^{+}$cells in the $0 B$ of both control $\left(\right.$ Notch $1^{+/+}$) and Notch1 $\mathrm{CKO}\left(\right.$ Notch $1^{\Delta / \Delta}$ ) mice are NeuN ${ }^{+}$neurons (arrowheads). $\boldsymbol{M}, \mathbf{N}$, Ablation of Notch1 dramatically reduces the number of newly generated neurons (X-Gal stained blue) in the $0 \mathrm{~B} 45 \mathrm{~d}$ after TAM treatment. Inserts shows DAPI staining of the corresponding sections. $\boldsymbol{O}, \boldsymbol{P}$, Quantification of recombined cells in the granule cell $(\boldsymbol{O})$ and glomerular cell layers $(\boldsymbol{P})$ of the $0 B$ of control (Notch $1^{+/+} ; n=$

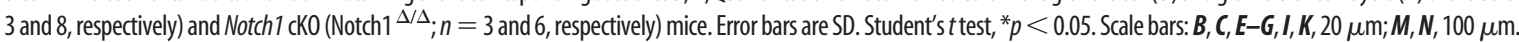

in $\mathrm{bGal}^{+} \mathrm{NeuN}^{+}$granular neurons (reduced 52\%; Fig. 2O) and a trend toward reduction in $\mathrm{bGal}^{+} \mathrm{NeuN}^{+}$glomerular neurons (reduced 46\%; Fig. 2P) $15 \mathrm{~d}$ after Notch1-ablation.

Although the number of $\mathrm{bGal}^{+} \mathrm{NeuN}^{+}$neurons increased with time, newborn $\mathrm{OB}$ neurons remained consistently lower in Notch $1 \mathrm{cKO}$ than in control mice $45 \mathrm{~d}$ after Notch 1 ablation (Fig.

$\leftarrow$

(Figure legend continued.) interdigitated into the ependymal lining. $\boldsymbol{E}$, Some astrocytes $\left(\mathrm{GFAP}^{+}\right)$are in the cell cycle (PCNA ${ }^{+}$, arrowheads) and some are not (GFAP ${ }^{+} \mathrm{PCNA}{ }^{-}$, open arrowheads). SVZ astrocytes have lower levels of Notch1 compared with clustered putative neuroblasts (arrows). $\boldsymbol{F}$, Neurogenic TAPs (Ascl1 ${ }^{+}$) express Notch 1 (arrowhead) comparable to other SVZ cells (arrows). G, Dcx ${ }^{+}$neuroblasts (arrowhead) also express Notch1 (Nyfeler et al., 2005). Str, striatum; $C$, corpus callosum. Scale bars: $\boldsymbol{B}, 100 \mu \mathrm{m} ; \mathbf{D}-\mathbf{G}, 20 \mu \mathrm{m}$.
$2 O, P)$. Thus, ablation of Notch 1 from the targeted progenitor cells resulted in a persistent defect in neurogenesis, indicating the requirement of Notch1 for the continued production of neuroblasts and OB neurons. The Notch 1 cKO phenotype was distinct to that caused by loss of RBP-J, the key transcriptional component of the Notch cascade, which resulted in an increase in neuroblasts in the SVZ and a burst of OB neuron formation (Carlén et al., 2009; Fujimoto et al., 2009; Imayoshi et al., 2010).

\section{Ablation of Notch1 leads to a loss of mitotic progenitors and neuroblasts in the SVZ}

NSCs generate mitotically active $\left(\mathrm{PCNA}^{+}\right)$progeny that include TAPs and neuroblasts. bGal ${ }^{+} \mathrm{PCNA}^{+}$cells were reduced by $>60 \%$ in the SVZ of the Notch1 cKO compared with control 
A
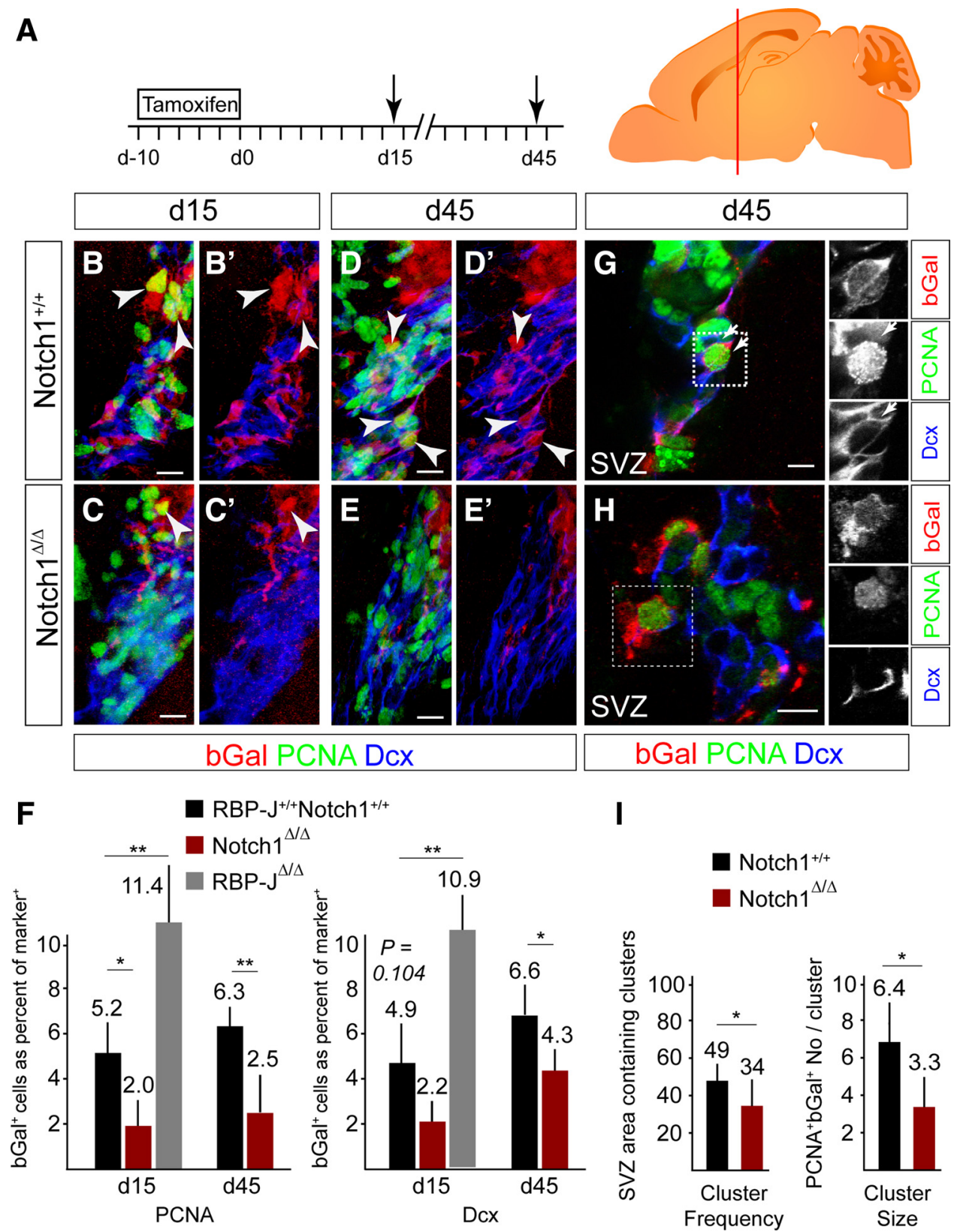

Figure 3. Notch 1 ablation results in a persistent loss of progenitors in the SVZ. A, Scheme of the TAM induction protocol in adult mice followed by a 15 or $45 \mathrm{~d}$ chase (death, arrow). Brains were

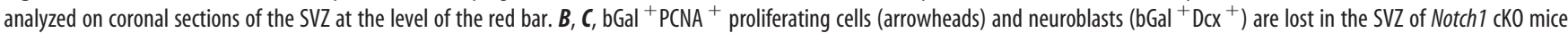
$\left(\right.$ Notch $\left.1^{\Delta / \Delta} ; \boldsymbol{C}\right)$ compared with controls (Notch $\left.1^{+/+} ; \boldsymbol{B}\right) 15$ d after TAM treatment. $\boldsymbol{D}, \boldsymbol{E}$, Loss of proliferating cells (bGal ${ }^{+} \mathrm{PCNA}{ }^{+}$; arrowheads) and neuroblasts (bGal ${ }^{+}$Dcx ${ }^{+}$) in the SVZ of Notch1 cKO mice $\left(\right.$ Notch $\left.1^{\Delta / \Delta} ; \boldsymbol{E}\right)$ compared with controls (Notch $\left.{ }^{+/+} ; \boldsymbol{D}\right)$ even 45 d after the recombination. $\boldsymbol{F}$, Quantification of bGal ${ }^{+}$PCNA ${ }^{+}$proliferating cells and neuroblasts in the SVZ of Notch1 cKO $\left(\right.$ Notch $\left.1^{\Delta / \Delta} ; n=3-4\right), R B P-J$ CKO (RBP-J $\left.{ }^{\Delta / \Delta} ; n=3\right)$, and control (RBP-J ${ }^{+/+}$Notch $\left.^{+/+} ; n=3-4\right)$ animals. G, Sparse recombination enables cell-autonomous cluster analysis of the progeny of Nestin:: creER ${ }^{T 2}$-expressing NSCs $\left(\mathrm{bGal}^{+}\right.$) including proliferating cells (bGal, $\mathrm{PCNA}{ }^{+}$; arrows) in the SVZ. $\boldsymbol{H}$, bGal ${ }^{+}$neuroblasts [Doublecortin (Dcx ${ }^{+}$)] in the RMS are clustered, consistent with having a common origin. $I$, Quantification of clusters of recombined proliferating cells and the number of bGal ${ }^{+}$PCNA ${ }^{+}$cells per cluster in Notch1 cKO (Notch1 $\left.{ }^{\Delta / \Delta ;} ; n=6\right)$ and control (Notch1 ${ }^{+/+}$; $n=7)$ animals. Probability of recombined clusters per $6.25 \times 10^{5} \mu \mathrm{m}^{3}$ of the SVZ. Error bars are SD. Student's $t$ test, ${ }^{*} p<0.05,{ }^{* *} p<0.001$. Scale bars, $20 \mu \mathrm{m}$.

animals both 15 and $45 \mathrm{~d}$ after TAM induction, indicating a persistent loss of mitotic progenitors (Fig. 3A-E). Fewer $\mathrm{bGal}^{+} \mathrm{Dcx}^{+}$neuroblasts were present in the SVZ of Notch $1 \mathrm{cKO}$ mice at both time points, recapitulating the reduction observed in the RMS (Fig. 3B-E). The relative reductions in $\mathrm{bGal}^{+} \mathrm{PCNA}^{+}$ cells (mostly TAPs) and bGal ${ }^{+} \mathrm{Dcx}^{+}$neuroblasts in the Notch1 cKO were comparable and persistent (Fig. $3 F$ ), and as the ratio of $\mathrm{bGal}^{+}$TAPs to bGal ${ }^{+}$neuroblasts in the Notch1 cKO did not change between day 15 and 45, we excluded a selective loss of either population (Fig. $3 F$ ). This was supported by an absence of increased cell death in Notch1 cKO mice (data not shown). A possible explanation for these observations was a decreased production of TAPs in the absence of Notch1. In contrast, we found that ablation of RBP-J using the same strategy resulted in a significant $\left(2.2\right.$-fold) increase in $\mathrm{bGal}^{+} \mathrm{PCNA}^{+}$cells and $\mathrm{bGal}^{+} \mathrm{Dcx}^{+}$neuroblasts at $15 \mathrm{~d}$ (Fig. $3 F$ and data not shown). We interpreted this to indicate a precocious activation of NSCs in the absence of RBP-J.

NSCs are sessile in niches distributed throughout the SVZ (Doetsch et al., 1997). In control mice, sparse genetic labeling 


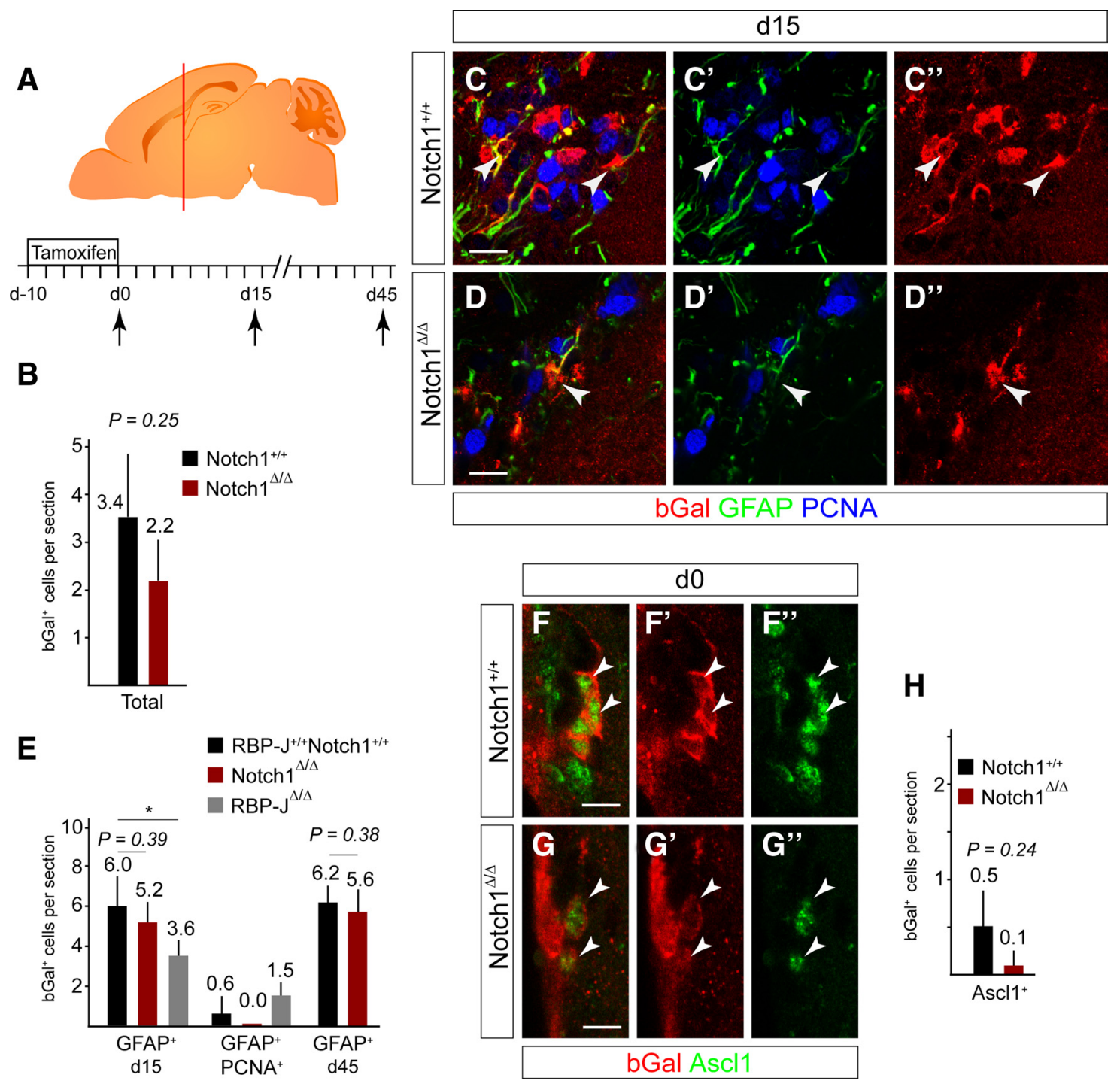

Figure 4. Notch 1 ablation does not result in a loss of GFAP ${ }^{+}$NSC. $A$, Ten day TAM induction protocol in adult mice followed by 0,15 , or $45 \mathrm{~d}$ chase (death, arrow). Brains were analyzed on coronal sections at the level of the red bar. $\boldsymbol{B}$, Ablation of Notch1 did not significantly affect the total number of bGal ${ }^{+}$cells at day 0. Notch1 $\mathrm{cKO}\left(\mathrm{Notch} 1^{\Delta / \Delta} ; n=3\right)$ and control $\left(\right.$ Notch $\left.1^{+/+} ; n=3\right)$ animals. C, Consistent with targeting early progenitors, a minor cell population are bGal ${ }^{+}$in the subependymal layer of the SVZ in control animals (Notch ${ }^{+/+}$).

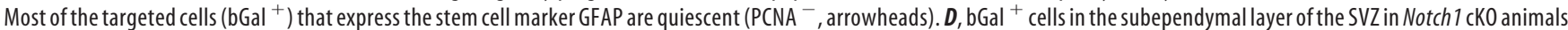
$\left(\right.$ Notch $1^{\Delta / \Delta}$ ) still express GFAP (arrowhead). E, Notch1 ablation does not alter the number of bGal ${ }^{+}$cells that expressed GFAP ${ }^{+}$in the subependymal layer of the SVZ and proliferation $(\mathrm{PCNA})$ of bGal ${ }^{+} \mathrm{GFAP}{ }^{+}$cells was also not increased. In contrast, $R B P$-J ablation $\left(\mathrm{RBP}-\mathrm{J}^{\Delta / \Delta}\right.$ ) results in reduced bGal ${ }^{+} \mathrm{GFAP}^{+}$cells in the subependymal layer. Notch1 $\mathrm{cKO}$ (Notch $1{ }^{\Delta / \Delta}$; $n=3$ at day 15 and 4 at day 45$), R B P-J$ CKO (RBP-J $\left.{ }^{\Delta / \Delta} ; n=3\right)$, and control (RBP-J ${ }^{+/+}$Notch $1^{+/+} ; n=7$ at day 15 and 4 at day 45 ) animals. $F$, bGal ${ }^{+}$cells rarely express the TAP marker Ascl1 in control mice immediately after TAM treatment (day 0: Notch $1^{+/+}$; arrowheads). G, Ascl1 ${ }^{+}$recombined cells are detectable in Notch1 $\mathrm{cKO}$ mice and are not increased (Notch ${ }^{\Delta / \Delta}$, arrowheads). $\boldsymbol{H}$, Ablation of Notch 1 did not significantly affect the number of bGal ${ }^{+}$Ascl1 ${ }^{+}$TAPs at d0. Notch $1 \mathrm{cKO}\left(\right.$ Notch $\left.{ }^{\Delta / \Delta}, n=3\right)$ and control (Notch $1{ }^{+/+}, n=3$ ) animals. Error bars are SD. Student's $t$ test, ${ }^{*} p<0.05$. Scale bars, $10 \mu \mathrm{m}$.

gave rise to clusters of $\mathrm{bGal}^{+}$proliferating cells $\left(\mathrm{PCNA}^{+}\right)$in the lateral ventricle wall at a frequency that reflected the density of targeted aNSCs (Fig. 3G-I). Cells within a cluster are potentially the progeny of a single NSC. bGal ${ }^{+}$cell clusters were significantly reduced in Notch1 cKO mice compared with controls (probability of a cluster being present in $6.25 \times 10^{5}$ $\mu \mathrm{m}^{3}$ of SVZ) $(34 \pm 14 \%$ vs $49 \pm 12 \%$, mean \pm SD, respectively; Fig. $3 G-I)$. We suggest this reflects a loss of targeted aNSCs (reduced number and density) in the Notch1 cKO that culminated in the decreased TAP and neuroblast populations. In addition, and in support of Notch1 ablation reducing mitotic progenitors, the number of cells within the individual clusters was reduced in Notch $1 \mathrm{cKO}$ animals compared with controls (Fig. 3I).

\section{Quiescent Notch1-deficient NSCs do not precociously differentiate in the SVZ}

Ablation of Notch1 from Nestin-expressing SVZ progenitors resulted in a persistent reduction in neurogenesis. Previously we have shown that the $\mathrm{bGal}^{+} \mathrm{GFAP}^{+}$cells in the SVZ of TAMinduced Nestin::creER $R^{T 2}$ Rosa26R mice express Sox 2 and are neurogenic NSCs (Giachino and Taylor, 2009). We examined targeted cells in the SVZ and focused on $\mathrm{bGal}^{+} \mathrm{GFAP}^{+}$putative NSCs (Fig. 4A-E). Immediately after TAM induction, comparable numbers of $\mathrm{bGal}^{+}$subependymal cells were detected in the SVZ of Notch $1 \mathrm{cKO}$ and control mice $(2.2 \pm 0.8$ and $3.4 \pm 1.3$ cells/section, respectively; mean \pm SD; Fig. $4 B)$. The number of $\mathrm{bGal}^{+} \mathrm{GFAP}^{+}$cells in the SVZ of Notch 1 cKO at day 0 was also not significantly different to controls ( $p=0.68$; data not shown). 
Therefore, loss of Notch1 did not lead to an immediate decrease in $\mathrm{GFAP}^{+}$putative NSCs.

We addressed whether loss of Notch 1 resulted in a transition of NSCs to TAPs without entry into cell cycle. bGal ${ }^{+} \mathrm{Ascl} 1^{+}$ TAPs were present in control animals immediately after $(0 \mathrm{~d})$ TAM treatment $(0.5 \pm 0.4$ cells/section mean $\pm \mathrm{SD})$ and were not increased in Notch 1 cKO but showed a trend toward reduction $(0.1 \pm 0.1$ cells/section, mean \pm SD; Fig. $4 F-H)$. In summary, Notch 1 cKO in SVZ NSCs did not lead to cell cycle entry or precocious onset of differentiation and is therefore phenotypically distinct to complete suppression of canonical Notch signaling through deletion of RBP-J (Imayoshi et al., 2010).

Fifteen days after TAM induction, the number of $\mathrm{bGal}^{+} \mathrm{GFAP}^{+}$cells in Notch1 cKO $(5.2 \pm 1.0$ cells/section, mean \pm SD of total SVZ cells) remained comparable to controls $(6.0 \pm 1.6$ cells/section, mean \pm SD of total SVZ cells; Fig. $4 C-E)$. $\mathrm{bGal}^{+} \mathrm{GFAP}^{+} \mathrm{PCNA}^{+}$cells were not detected in Notch $1 \mathrm{cKO}$ or controls, indicating that quiescent NSCs (qNSCs) had not been driven into the cell cycle by ablating Notch1 (Fig. 4E). Furthermore, the number of $\mathrm{bGal}^{+} \mathrm{GFAP}^{+}$cells in Notch $1 \mathrm{cKO}$ animals was comparable to controls $45 \mathrm{~d}$ after TAM treatment (Fig. $4 \mathrm{E}$ ). Hence, qNSCs were targeted but not activated by the Notch1 cKO. In contrast, $15 \mathrm{~d}$ after ablation of RBP-J using the same strategy, $\mathrm{bGal}^{+} \mathrm{GFAP}^{+}$NSCs were reduced by $40 \%$ and $\mathrm{bGal}^{+} \mathrm{GFAP}^{+} \mathrm{PCNA}^{+}$cells were increased compared with controls (Fig. 4E). These findings confirme that RBP-J-deficient NSCs precociously activate and differentiate (Imayoshi et al., 2010). Together, these results indicated that Notch 1 is required to maintain the correct number of neurogenic aNSCs in the SVZ; however, although qNSCs require canonical Notch signaling (RBP-J), they are not dependent upon Notch1.

\section{The Notch1-deficient NSCs do not regenerate the SVZ correctly}

A remarkable feature of the SVZ is its ability to regenerate after injury (Doetsch et al., 1999a,b). Six days of treatment with the antimitotic AraC results in a complete loss of TAPs and neuroblasts in the SVZ but spares quiescent regenerative NSCs (Fig. 5A) (Doetsch et al., 1999a). Regenerative NSCs become active upon killing mitotic cells with AraC and regenerate the SVZ. We speculated that AraC treatment combined with Notch $1 \mathrm{cKO}$ would enable us to focus on the role of Notch1 in quiescent regenerative NSCs and addressed whether Notch1 is required for the regeneration as well as homeostatic neurogenic processes. We induced mice with TAM before degeneration (Fig. 5A) and confirmed a complete loss of proliferating cells and neuroblasts in the SVZ (Giachino and Taylor, 2009). bGal ${ }^{+}$ cells in the SVZ survived AraC treatment (Fig. 5B,C), including $\mathrm{bGal}^{+} \mathrm{GFAP}^{+}$NSCs. Following $15 \mathrm{~d}$ of regeneration, $\mathrm{bGal}^{+}$cells contributed to the reinstated neurogenesis in control animals and $\mathrm{bGal}^{+} \mathrm{Dcx}^{+}$were present in the regenerated SVZ, but the proportion of $\mathrm{Dcx}^{+}$neuroblasts that were $\mathrm{bGal}^{+}$was significantly reduced in Notch 1 cKO $(5.0 \pm 0.1 \%$ vs $2.7 \pm 0.8 \%$, mean \pm SD; Fig. $5 D)$. Thus, although the number of bGal ${ }^{+} \mathrm{GFAP}^{+}$NSCs in the Notch1 cKOs was comparable to controls before degeneration, Notch1 was obviously required for effective regeneration of neuroblasts after lesion. These findings are similar to those made after deletion of RBP-J (Imayoshi et al., 2010).

We addressed whether the loss of newborn neuroblasts in the regenerated SVZ of Notch1 cKO correlated with a loss of proliferating cells. bGal ${ }^{+} \mathrm{PCNA}^{+}$cells were readily detectable in the regenerated $\mathrm{SVZ}$ of control animals $(3.5 \pm 1.3 \%$, mean $\pm \mathrm{SD})$ but were a significantly smaller population in Notch1 cKO (1.4 \pm
$0.4 \%$, mean \pm SD; Fig. $5 E-G$ ). These findings are in agreement with previous reports showing a block of regeneration following RBP-J deletion; however, whereas loss of RBP-J affected qNSC numbers before degeneration, Notch1 ablation did not (Fig. 4) (Imayoshi et al., 2010).

\section{qNSCs that enter the cell cycle during regeneration become dependent on Notch1}

Regenerative NSCs enter the cell cycle within $24 \mathrm{~h}$ of stopping AraC treatment and return to a quiescent state after generating TAPs (Doetsch et al., 1999a). This suggests that proliferative regenerative NSCs may resemble neurogenic aNSCs, which we had shown are Notch1-dependent. bGal ${ }^{+} \mathrm{GFAP}^{+}$NSCs were reduced in the regenerated SVZ of the Notch1 cKO compared with control mice (Fig. 6A-C). Therefore, we addressed whether the remaining bGal ${ }^{+} \mathrm{GFAP}^{+}$cells in the regenerated SVZ had passed through S-phase of the cell cycle early during the regeneration process. We used a BrdU label-retention paradigm to mark mitotic cells that had proliferated but remained in the regenerated SVZ (Fig. $5 \mathrm{~A}$ ). The proportion of the $\mathrm{bGal}^{+}$cells that were BrdU label-retaining was reduced in the regenerated SVZ of Notch1 cKO mice (Fig. $6 D-F$ ). Some bGal ${ }^{+} \mathrm{GFAP}^{+}$cells in the regenerated SVZ of control mice were $\mathrm{BrdU}^{+}(2.3 \pm 1.0$ cells/section, mean $\pm \mathrm{SD}$ ), indicating activation and a subsequent return to quiescence; these tended to be less frequent in the absence of Notch 1 ( $1.2 \pm 0.6$ cells/section, mean \pm SD; Fig. $6 D-G)$. Therefore, quiescent regenerative NSCs that were previously insensitive to Notch1 deletion in Notch 1 cKO mice had potentially become activated by the lesion but failed to return to the quiescent state. Moreover, we did not detect bGal ${ }^{+} \mathrm{GFAP}^{+} \mathrm{PCNA}^{+}$ cells in controls or Notch1 cKO (Fig. 6G-I), indicating that continuous proliferation of regenerative NSCs could not explain the lack of reentry of Notch1-deficient NSCs into quiescence. $\mathrm{As} \mathrm{bGal}^{+} \mathrm{GFAP}^{+}$cells were not reduced in the Notch $1 \mathrm{cKO}$ before AraC treatment (Fig. 4), regenerative NSCs require Notch1 once they enter the cell cycle to contribute to SVZ repair. Therefore, Notch 1 was required by regenerative NSCs to initiate neurogenesis but also for them to remain as stem cells in the regenerating SVZ.

\section{Quiescent Notch1-deficient NSCs decline with age}

We hypothesized that qNSCs may be a reserve population for replenishing the aNSC pool. As qNSCs do not rely on Notch1 but become Notch1-dependent once induced to proliferate by a lesion, we speculated that if Notch1-deficient qNSCs sporadically activate, they should diminish with age due to the lack of the Notch1 maintenance signal. We analyzed bGal ${ }^{+} \mathrm{GFAP}^{+}$cells in aged mice 1 year after Notch1-ablation (Fig. 6J). Indeed, $\mathrm{bGal}^{+} \mathrm{GFAP}^{+}$cells were significantly reduced in aged Notch1 cKO mice $(2.8 \pm 1.34$ cells/section, mean \pm SD) compared with aged controls $(5.5 \pm 1.62$ cells/section, mean \pm SD; Fig. $6 K-M)$. Therefore, Notch1-deficient qNSCs are lost in aged mice, suggesting they may activate over time, potentially to replenish an exhausted aNSC pool and thereby become Notch1-dependent.

\section{Multiple Notch receptors are expressed in the adult neurogenic SVZ}

As qNSCs depend on canonical Notch signaling for maintenance but are not directly affected by the loss of Notch1, we speculated redundancy with other Notch family members in the qNSCs. We analyzed the expression of Notch2 and Notch3 in the adult SVZ. Notch2 and Notch3 were expressed with a similar pattern to that of Notch1 (Fig. 7A-C). Like Notch1, Notch2 and Notch3 were 

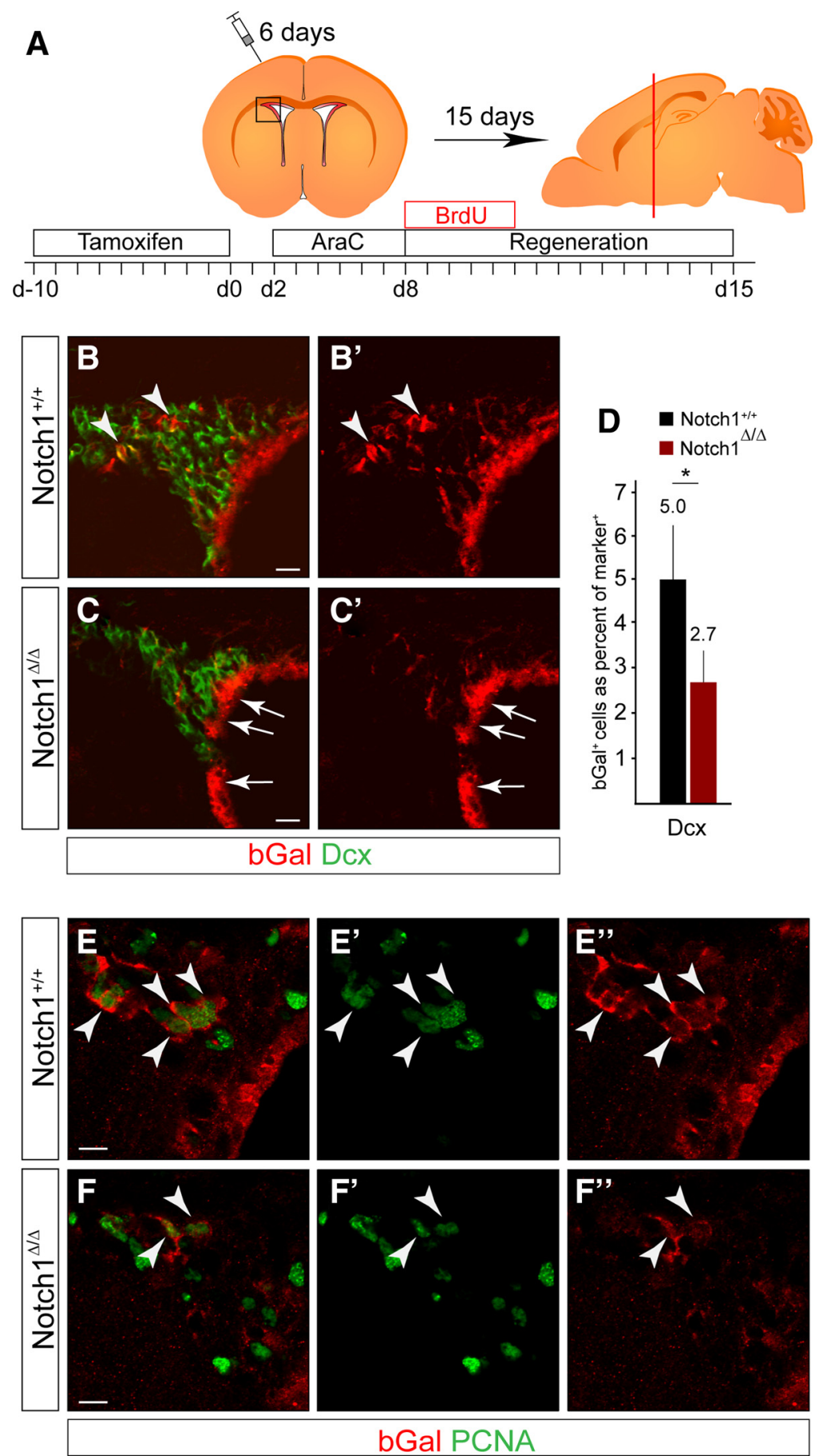

\section{G}

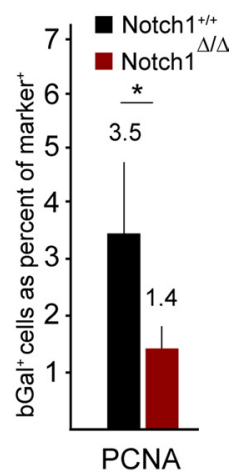

bGal PCNA

Figure 5. Notch1 is required for regeneration of neurogenic progenitors in the SVZ.A, Schematic overview of the experimental paradigm and regenerative process. Notch ${ }^{\text {lox/lox }}$ and control littermates were induced with TAM for $10 \mathrm{~d}$ before intracranial infusion of AraC. Mice were treated with BrdU during the first 5 d of regeneration. Brains were analyzed on coronal sections at the level shown by the red bar. $\boldsymbol{B}, \mathrm{bGal}{ }^{+}$ dormant NSCs activate following AraC-induced degeneration and contribute to regeneration in the SVZ by generating newborn bGal ${ }^{+} \mathrm{Dcx}{ }^{+}$neuroblasts (arrowheads). $C$, bGal ${ }^{+}$cells are reduced in the regenerated SVZ of Notch1 cKO (Notch $1^{\Delta / \Delta}$ ) animals. The ependymal layer is not affected in the Notch1 cKO even after AraC treatment (arrows). D, Quantification of bGal ${ }^{+}$neuroblasts (Dcx ${ }^{+}$) in the regenerated SVZ of Notch1 CKO (Notch $\left.{ }^{\Delta / \Delta} ; n=4\right)$ and control (Notch $\left.1^{+/+} ; n=4\right)$ animals. $E$, bGal ${ }^{+}$NSCs generate clusters of proliferating progeny (bGal ${ }^{+}$PCNA ${ }^{+}$, arrowheads) in the regenerated SVZ of controls $\left(\right.$ Notch $\left.1^{+/+}\right) \cdot F_{,}$bGal ${ }^{+}$PCNA ${ }^{+}$cells are reduced in the regenerated SVZ of Notch1 CKO (Notch1 ${ }^{\Delta / \Delta}$ ) animals (arrowheads). G, Quantification ofbGal ${ }^{+}$proliferating cells $\left(\right.$PCNA ${ }^{+}$) in the regenerated SVZ of Notch1 CKO (Notch1 $\left.{ }^{\Delta / \Delta} ; n=4\right)$ and control (Notch1 $\left.{ }^{+/+} ; n=4\right)$ animals. Error bars are SD. Student's t test, ${ }^{*} p<0.05$. Scale bars: $B, C, 20 \mu \mathrm{m} ; \boldsymbol{E}, \boldsymbol{F}, 10 \mu \mathrm{m}$.

expressed by both $\mathrm{GFAP}^{+}$putative NSCs and GFAP ${ }^{-}$cells (Fig. $7 D-F)$. However, whereas Notch2 was expressed by putative neuroblasts (Fig. $7 E$ ), Notch3 localized predominantly with GFAP in the SVZ (Fig. $7 F, G$ ). Hence, Notch2 and Notch3 are expressed in $\mathrm{GFAP}^{+}$putative NSCs and could functionally compensate Notch1 deficiency in quiescent cells.

\section{Discussion}

Notch1 regulates homeostatic neurogenesis in the adult forebrain

The mechanisms controlling neurogensis and regeneration in the adult SVZ are not fully understood. Notch signaling has been 

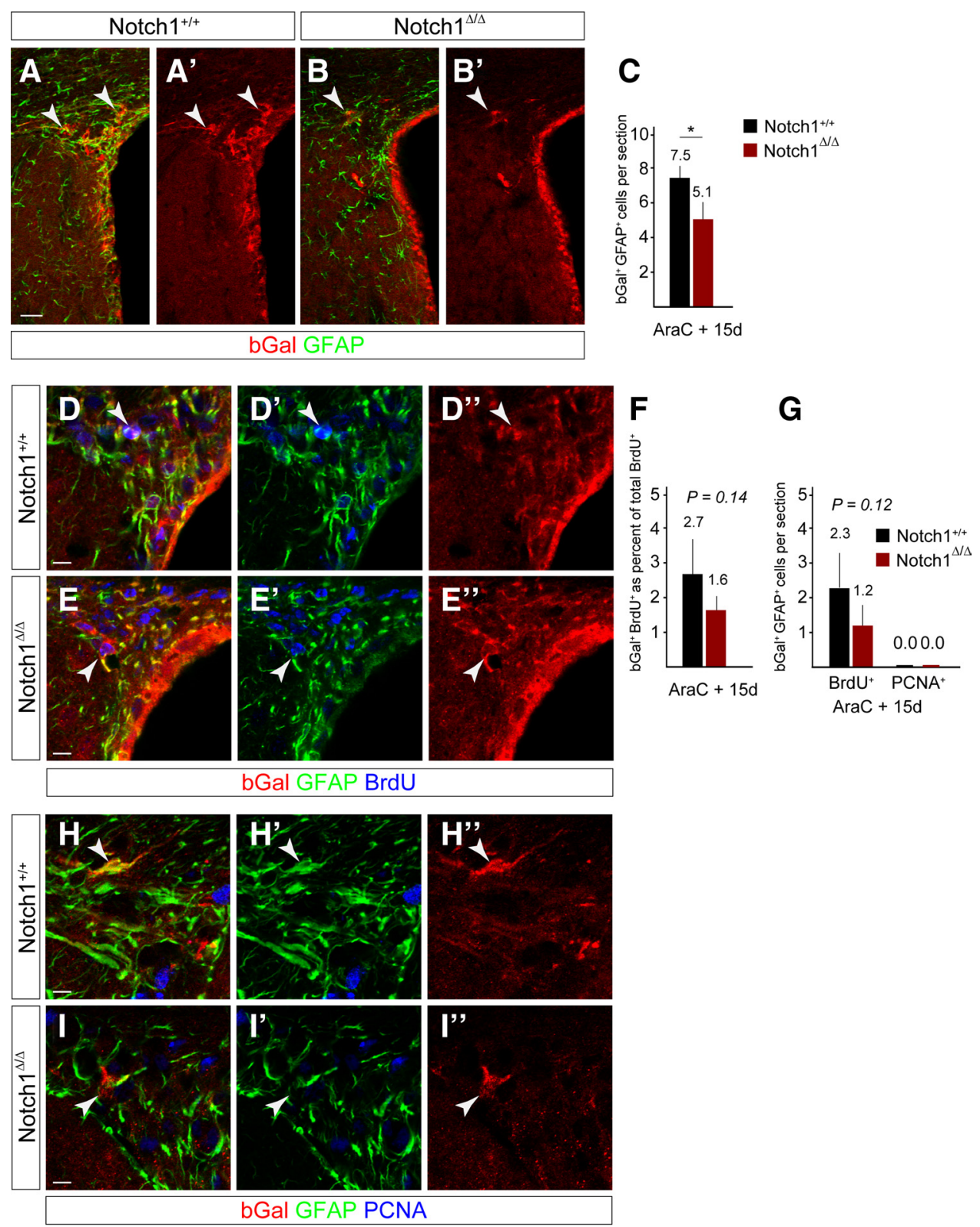

$$
\text { J }
$$
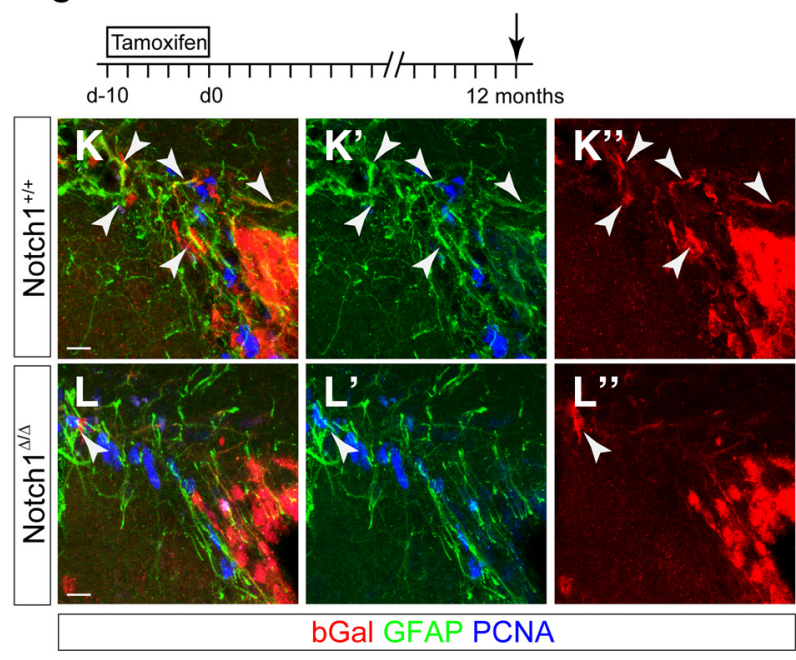

M

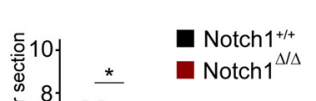

Figure 6. Notch1 ablation results in a reduction in GFAP ${ }^{+}$dormant NSCs in the regenerated SVZ and during aging. $A, B, b G a l^{+}$cells (arrowheads) in the regenerated SVZ $15 \mathrm{~d}$ after stopping AraC infusion are reduced in the Notch1-ablated (Notch ${ }^{\Delta / \Delta}$ ) compared with control (Notch1 ${ }^{+/+}$) animals. C, Ablation of Notch1 (Notch ${ }^{\Delta / \Delta} ; n=5$ ) before regeneration (Figure legend continues.) 

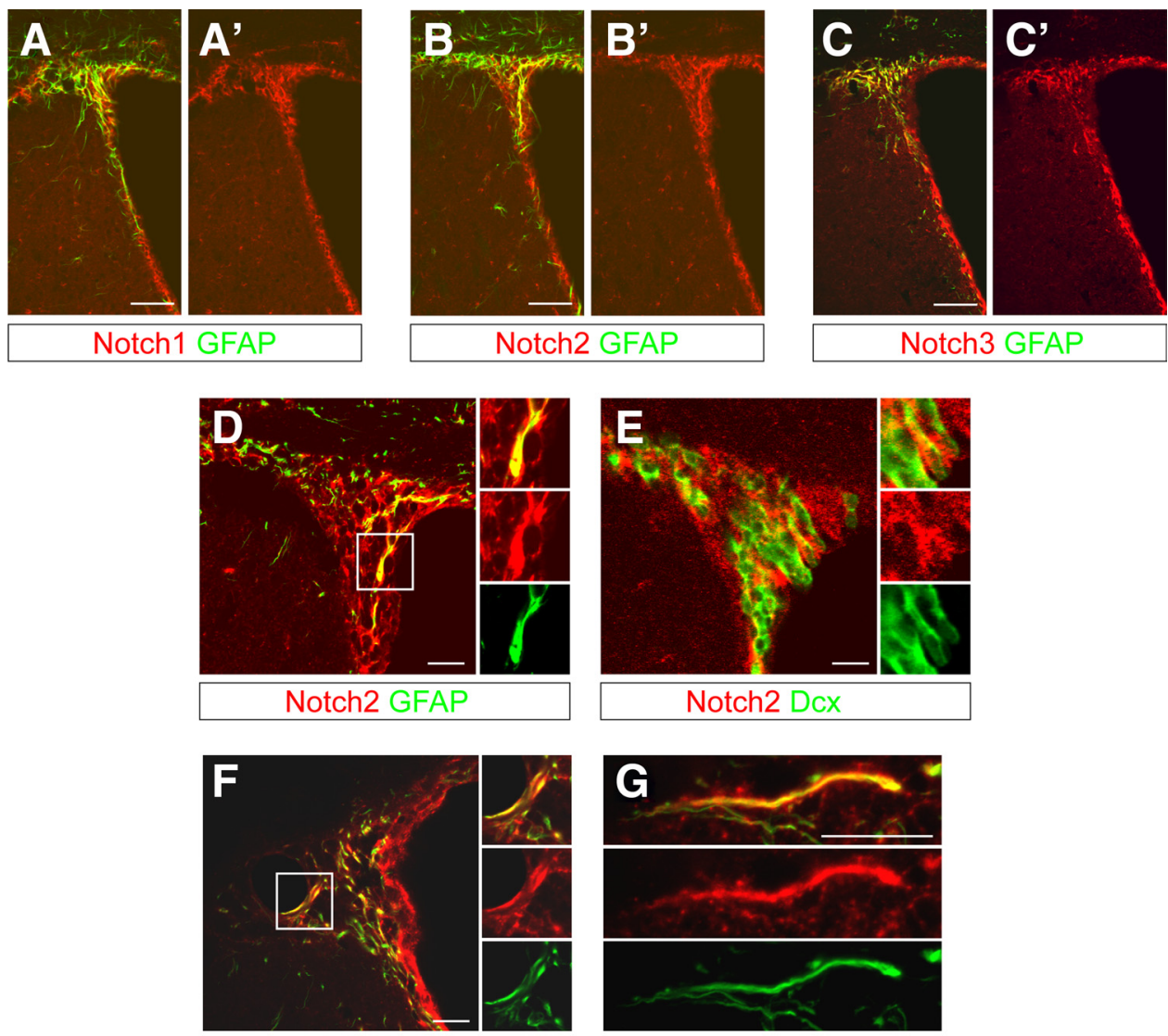

Notch3 GFAP

Notch3 GFAP

Figure 7. Notch2 and Notch3 are expressed in the SVZ with a similar pattern to Notch1. $A$, Notch1 is expressed in the SVZ of adult mice by GFAP ${ }^{+}$and GFAP ${ }^{-}$cells. $B$, C, Consecutive sections stained with anti-Notch2 $(\boldsymbol{B})$ or anti-Notch3 $(\boldsymbol{C})$ antibodies showing a comparable expression pattern in the SVZ to that of Notch1. $\boldsymbol{D}$, Notch2 is expressed by GFAP ${ }^{-}$cells in the subependymal region of the SVZ but also by GFAP ${ }^{+}$SVZ astrocytes and putative NSCs in close proximity to or making contact with the lateral ventricle. E, Some Notch2 ${ }^{+} \mathrm{GFAP}^{-}$cells are Doublecortin ${ }^{+}$(Dcx $^{+}$) neuroblasts. $\boldsymbol{F}, \mathbf{G}$, Notch3 is prominently expressed by GFAP ${ }^{+}$SVZ astrocytes. Scale bars: $\boldsymbol{A}-\mathbf{C}, 100 \mu \mathrm{m} ; \mathbf{D}-\mathbf{G}, 20 \mu \mathrm{m}$.

studied extensively during neural development (Louvi and Artavanis-Tsakonas, 2006). However, its role in adult neurogenesis is less clear. The specific role of Notch1 in adult SVZ neurogenesis has not been determined. Previously we have shown that Notch1 is required to maintain adult SVZ-derived NSCs in vitro (Nyfeler et al., 2005). Ablation of Notch1 from self-replicating multipotent neurosphere cells resulted in a loss of sphereforming potential. Here, we analyzed Notch1 loss-of-function in vivo and describe a pivotal role for Notch1 in the regulation of adult SVZ neurogenesis. We also uncovered distinct differences in Notch1 requirements of NSCs between their active neurogenic

\footnotetext{
(Figure legend continued.) results in a reduction in $\mathrm{bGal}^{+} \mathrm{GFAP}^{+}$cells compared with control (Notch $\left.{ }^{+/+} ; n=5\right)$ animals. $\boldsymbol{D}, \boldsymbol{E}$, BrdU label-retaining cells are present in the regenerated SVZ of control (Notch $1^{+/+}$) and Notch $1 \mathrm{CKO}\left(\right.$ Notch $^{\Delta / \Delta}{ }^{\Delta /}$ ) animals and some express GFAP (arrowheads). $\boldsymbol{F}_{\text {, bGal }}{ }^{+}$BrdU-retaining cells are slightly reduced in the regenerated SVZ following deletion of Notch1 (Notch $1^{\Delta / \Delta} ; n=5$ ) compared with control (Notch1 ${ }^{+/+} ; n=5$ ) animals. $\mathbf{G}$, The number of bGal ${ }^{+} \mathrm{GFAP}^{+} \mathrm{BrdU}$-retaining cells is slightly reduced in the regenerated SVZ of Notch1 CKO (Notch $\left.1^{\Delta / \Delta} ; n=5\right)$ compared with control (Notch1 ${ }^{+/+} ; n=5$ ) animals. bGal ${ }^{+} \mathrm{GFAP}^{+}$cells in the Notch1 $\mathrm{CKO}$ SVZ do not remain mitotically active $\left(\mathrm{PCNA}^{+}\right)$ after regeneration. $\boldsymbol{H}, \boldsymbol{I}$, In both control and Notch1 $\mathrm{CKO}$ animals, $\mathrm{GFAP}^{+}$cells return to a quiescent state ( $\mathrm{PCNA}{ }^{-}$) in the regenerated SVZ (arrowheads). J, $10 \mathrm{~d}$ TAM induction protocol in adult mice followed by 12 -month chase (death, arrow). $\boldsymbol{K}-\boldsymbol{M}$, Ablation of Notch 1 in young adult mice (Notch1 ${ }^{\Delta / \Delta} ; n=4$ ) results in a reduction in bGal ${ }^{+} \mathrm{GFAP}^{+}$cells when analyzed 1 year later compared with control mice (Notch $\left.1^{+/+} ; n=4\right)$ ). Error bars are SD. Student's $t$ test, ${ }^{*} p<0.05$. Scale bars: $\boldsymbol{A}, 25 \mu \mathrm{m} ; \boldsymbol{D}, \boldsymbol{E}, \boldsymbol{H}, \boldsymbol{I}, \boldsymbol{K}, \boldsymbol{L}, 10 \mu \mathrm{m}$.
}

and quiescent states and the functions of RBP-J. In the absence of Notch1, aNSCs are lost, which is a comparable finding to those made following deletion of RBP-J (Imayoshi et al., 2010). However, whereas deletion of RBP-J caused a temporary increase in mitotic cells, deletion of Notch1 did not. Furthermore, loss of RBP-J resulted in qNSCs becoming mitotically active. This implies that canonical Notch signaling through RBP-J is required for maintenance of qNSCs but that Notch1 is not. However, the effects of loss of RBP-J are in keeping with canonical Notch signaling playing multiple roles in adult neurogenesis, first suppressing proliferation and retaining NSCs in a quiescent state and secondly preventing differentiation of mitotic NSCs (Fujimoto et al., 2009; Imayoshi et al., 2010).

\section{Why doesn't Notch1-ablation induce proliferation and TAP} formation in the same way that loss of RBP-J does?

Notch signaling regulates proneural gene expression in SVZ progenitors, thereby suppressing differentiation (Nyfeler et al., 2005; Louvi and Artavanis-Tsakonas, 2006; Basak and Taylor, 2009). We propose that this is a key function of Notch 1 working through RBP-J in active NSCs of the SVZ. Although Notch1 is expressed by quiescent $\left(\mathrm{PCNA}^{-}\right)$NSCs, we do not have evidence for prococious differentiation of qNSCs or their entry into mitosis in its absence, unlike following the loss of RBP-J. A possible explanation for the differences in pheonotype between Notch1 and RBP-J cKO mice is that other members of the Notch family may induce 
the signals through RBP-J that repress proliferation in qNSCs (Chapouton et al., 2010). Alternatively, other Notch family members could functionally compensate the Notch1 deletion. During embryonic development, Notch1 plays a partially redundant role with other Notchs to regulate forebrain neurogenesis (Chambers et al., 2001; Yoon and Gaiano, 2005). Indeed, Notch 2 and Notch3 are expressed in the adult SVZ in a similar pattern to Notch1, including by $\mathrm{GFAP}^{+}$putative NSCs (Fig. 7A). Interestingly, Notch1 and Notch3 have been associated with activation versus quiescence of muscle stem cells, respectively (Carlson et al., 2008; Kitamoto and Hanaoka, 2010; Bjornson et al., 2012; Mourikis et al., 2012). It remains to be established whether Notch2 and/or Notch3 provide a maintenance signal for qNSCs in the absence of Notch1. This will require closer scrutiny in the future.

In contrast, the transcriptional repressor function of RBP-J may act to suppress proliferation in SVZ progenitors in the absence of Notch receptor activation, as RBP-J has Notch signaling-independent functions (Hori et al., 2008). TAPs in the SVZ do not normally display canonical Notch signaling and express Ascl1, a suppressed target of Notch (Basak and Taylor, 2007; Mizutani et al., 2007; Imayoshi et al., 2010). However, ablation of RBP-J induced aberrant Hes expression in the SVZ, synonymous with lost repression of Notch downstream targets (Imayoshi et al., 2010).

\section{Notch1 maintains active but not quiescent NSCs}

Unlike the loss of RBP-J, we found that ablation of Notch1 did not result in a transition of qNSCs to an active state or even a transient increase in $\mathrm{Ascl}^{+}{ }^{+}$or $\mathrm{Dcx}^{+}$cells and spared regenerative NSCs (Ables et al., 2010). Hence, we propose that NSCs only depend on Notch1 to prevent the transition to TAPs once they are activated and that Notch1 does not repress the switch from inactive to active states. Once activated, regenerative NSCs behaved like aNSCs and showed Notch1 dependence. This supports the theory that Notch1 is required to maintain self-renewal of NSCs once in a mitotic state but is dispensable during quiescence. It is intriguing to speculate that the role of Notch1 is linked to the cell cycle. Whether the progression of Notch-deficient NSCs to TAPs is associated with passing through the cell cycle is an interesting possibility and remains to be shown.

Our findings suggest that Notch1 signaling plays a central role during adult neurogenesis to inhibit commitment and promote/ enable self-renewal of aNSCs in a cell-autonomous manner. This is consistent with previous observations in muscle satellite cells where Notch signaling counteracts TGF- $\beta$-induced expression of cyclin-dependent kinase (CDK) inhibitors (p15, p16, p21, and p27) and promotes the active state (Carlson et al., 2008). The imbalance between reduced Notch and TGF- $\beta$ activity favors quiescence. TGF- $\beta$ signaling plays a similar repressive role in NSC proliferation during development and in the adult brain as does regulation of CDK inhibitors (Bruggeman et al., 2005; Molofsky et al., 2006; Fasano et al., 2007; Colak et al., 2008). It will be interesting to examine the balance between Notch and TGF- $\beta$ activity and CDK inhibition in regulating NSC activity. This also implies that a decline in Notch 1 activity within the neurogenic niche may cause a reduction in active neurogenesis without depleting qNSCs. This could be important in the aged brain where proliferation and aNSCs are both reduced but qNSCs remain (Lugert et al., 2010).

Why does neurogenesis continue in the absence of Notch1, albeit at a reduced rate?

Notch1 ablation does not affect qNSCs and thus the number of $\mathrm{bGal}^{+} \mathrm{GFAP}^{+} \mathrm{PCNA}^{-}$cells did not change, indicating that aNSC 
do not become quiescent in the absence of Notch1. However, newborn neurons are continually generated over $45 \mathrm{~d}$ after Notch1-ablation. Therefore, it is possible that in Notch1 cKO mice, Notch1-independent quiescent cells sporadically activate and enter the neurogenic pool over time and thus become dependent upon Notch1. These Notch1-deficient NSC lose NSC character and differentiate into neuroblasts without maintenance or expansion. The reduction in $\mathrm{bGal}^{+} \mathrm{GFAP}^{+}$putative NSCs in the aged Notch1 cKO SVZ lends support to this hypothesis and is further reinforced by our finding that activation of quiescent regnerative NSCs with AraC resulted in depletion of GFAP ${ }^{+}$cells in the SVZ of Notch1 cKO mice and to reduced regeneration.

It is tempting to speculate that aNSCs and activated regenerative NSCs in the adult brain resemble their embryonic predecessors, the radial glia, while qNSCs are unique to the adult germinal layers and display distinct molecular dependence. Our results describe fundamental functional and molecular differences in Notch signal requirements by NSCs in vivo that are dependent on activation state. It is likely that other somatic stem cell populations are specialized in a similar manner, as exemplified by muscle satellite cells; whether their fates are governed by similar mechanisms remains to be seen.

In summary, cell-autonomous Notch1 signaling is required by NSCs in the SVZ that generate the neuronal lineages in the entire adult OB layers. We demonstrate that Notch1-dependent NSCs contribute not only to adult neurogenesis but also to regeneration; however, surprisingly, qNSCs do not rely on Notch1 for their maintenance until activated (Fig. 8). We propose a model in which Notch1 regulates adult neurogenesis and regeneration primarily at the level of activated NSCs. This conserved mechanism and the molecular differences between homeostatic and regenerative stem cells may prove to be important targets for regenerative brain therapy.

\section{References}

Ables JL, Decarolis NA, Johnson MA, Rivera PD, Gao Z, Cooper DC, Radtke F, Hsieh J, Eisch AJ (2010) Notch1 is required for maintenance of the reservoir of adult hippocampal stem cells. J Neurosci 30:10484-10492.

Aguirre A, Rubio ME, Gallo V (2010) Notch and EGFR pathway interaction regulates neural stem cell number and self-renewal. Nature 467:323-327.

Balordi F, Fishell G (2007) Mosaic removal of hedgehog signaling in the adult SVZ reveals that the residual wild-type stem cells have a limited capacity for self-renewal. J Neurosci 27:14248-14259.

Basak O, Taylor V (2007) Identification of self-replicating multipotent progenitors in the embryonic nervous system by high Notch activity and Hes5 expression. Eur J Neurosci 25:1006-1022.

Basak O, Taylor V (2009) Stem cells of the adult mammalian brain and their niche. Cell Mol Life Sci 66:1057-1072.

Bjornson CR, Cheung TH, Liu L, Tripathi PV, Steeper KM, Rando TA (2012) Notch signaling is necessary to maintain quiescence in adult muscle stem cells. Stem Cells 30:232-242.

Breunig JJ, Silbereis J, Vaccarino FM, Sestan N, Rakic P (2007) Notch regulates cell fate and dendrite morphology of newborn neurons in the postnatal dentate gyrus. Proc Natl Acad Sci U S A 104:20558-20563.

Bruggeman SW, Valk-Lingbeek ME, van der Stoop PP, Jacobs JJ, Kieboom K, Tanger E, Hulsman D, Leung C, Arsenijevic Y, Marino S, van Lohuizen M (2005) Ink4a and Arf differentially affect cell proliferation and neural stem cell self-renewal in Bmil-deficient mice. Genes Dev 19:1438-1443.

Carlén M, Meletis K, Göritz C, Darsalia V, Evergren E, Tanigaki K, Amendola M, Barnabé-Heider F, Yeung MS, Naldini L, Honjo T, Kokaia Z, Shupliakov O, Cassidy RM, Lindvall O, Frisén J (2009) Forebrain ependymal cells are Notch-dependent and generate neuroblasts and astrocytes after stroke. Nat Neurosci 12:259-267.

Carlson ME, Hsu M, Conboy IM (2008) Imbalance between pSmad3 and Notch induces CDK inhibitors in old muscle stem cells. Nature 454:528-532.

Chambers CB, Peng Y, Nguyen H, Gaiano N, Fishell G, Nye JS (2001) Spa- tiotemporal selectivity of response to Notch1 signals in mammalian forebrain precursors. Development 128:689-702.

Chapouton P, Skupien P, Hesl B, Coolen M, Moore JC, Madelaine R, Kremmer E, Faus-Kessler T, Blader P, Lawson ND, Bally-Cuif L (2010) Notch activity levels control the balance between quiescence and recruitment of adult neural stem cells. J Neurosci 30:7961-7974.

Colak D, Mori T, Brill MS, Pfeifer A, Falk S, Deng C, Monteiro R, Mummery C, Sommer L, Götz M (2008) Adult neurogenesis requires Smad4mediated bone morphogenic protein signaling in stem cells. J Neurosci 28:434-446.

Coskun V, Wu H, Blanchi B, Tsao S, Kim K, Zhao J, Biancotti JC, Hutnick L, Krueger RC Jr, Fan G, de Vellis J, Sun YE (2008) CD133+ neural stem cells in the ependyma of mammalian postnatal forebrain. Proc Natl Acad Sci U S A 105:1026-1031.

Doetsch F, García-Verdugo JM, Alvarez-Buylla A (1997) Cellular composition and three-dimensional organization of the subventricular germinal zone in the adult mammalian brain. J Neurosci 17:5046-5061.

Doetsch F, García-Verdugo JM, Alvarez-Buylla A (1999a) Regeneration of a germinal layer in the adult mammalian brain. Proc Natl Acad Sci U S A 96:11619-11624.

Doetsch F, Caillé I, Lim DA, García-Verdugo JM, Alvarez-Buylla A (1999b) Subventricular zone astrocytes are neural stem cells in the adult mammalian brain. Cell 97:703-716.

Doetsch F, Petreanu L, Caille I, Garcia-Verdugo JM, Alvarez-Buylla A (2002) EGF converts transit-amplifying neurogenic precursors in the adult brain into multipotent stem cells. Neuron 36:1021-1034.

Ehm O, Göritz C, Covic M, Schäffner I, Schwarz TJ, Karaca E, Kempkes B, Kremmer E, Pfrieger FW, Espinosa L, Bigas A, Giachino C, Taylor V, Frisén J, Lie DC (2010) RBPJkappa-dependent signaling is essential for long-term maintenance of neural stem cells in the adult hippocampus. J Neurosci 30:13794-13807.

Fasano CA, Dimos JT, Ivanova NB, Lowry N, Lemischka IR, Temple S (2007) shRNA knockdown of Bmi-1 reveals a critical role for $\mathrm{p} 21-\mathrm{Rb}$ pathway in NSC self-renewal during development. Cell Stem Cell 1:87-99.

Fujimoto M, Takagi Y, Muraki K, Nozaki K, Yamamoto N, Tsuji M, Hashimoto N, Honjo T, Tanigaki K (2009) RBP-J promotes neuronal differentiation and inhibits oligodendroglial development in adult neurogenesis. Dev Biol 332:339-350.

Gage FH (2000) Mammalian neural stem cells. Science 287:1433-1438.

Giachino C, Taylor V (2009) Lineage analysis of quiescent regenerative stem cells in the adult brain by genetic labelling reveals spatially restricted neurogenic niches in the olfactory bulb. Eur J Neurosci 30:9-24.

Givogri MI, de Planell M, Galbiati F, Superchi D, Gritti A, Vescovi A, de Vellis J, Bongarzone ER (2006) Notch signaling in astrocytes and neuroblasts of the adult subventricular zone in health and after cortical injury. Dev Neurosci 28:81-91.

Hack MA, Saghatelyan A, de Chevigny A, Pfeifer A, Ashery-Padan R, Lledo PM, Götz M (2005) Neuronal fate determinants of adult olfactory bulb neurogenesis. Nat Neurosci 8:865-872.

Han H, Tanigaki K, Yamamoto N, Kuroda K, Yoshimoto M, Nakahata T, Ikuta K, Honjo T (2002) Inducible gene knockout of transcription factor recombination signal binding protein-J reveals its essential role in $\mathrm{T}$ versus B lineage decision. Int Immunol 14:637-645.

Hori K, Cholewa-Waclaw J, Nakada Y, Glasgow SM, Masui T, Henke RM, Wildner H, Martarelli B, Beres TM, Epstein JA, Magnuson MA, Macdonald RJ, Birchmeier C, Johnson JE (2008) A nonclassical bHLH Rbpj transcription factor complex is required for specification of GABAergic neurons independent of Notch signaling. Genes Dev 22:166-178.

Imayoshi I, Sakamoto M, Yamaguchi M, Mori K, Kageyama R (2010) Essential roles of Notch signaling in maintenance of neural stem cells in developing and adult brains. J Neurosci 30:3489-3498.

Jackson EL, Garcia-Verdugo JM, Gil-Perotin S, Roy M, Quinones-Hinojosa A, VandenBerg S, Alvarez-Buylla A (2006) PDGFR alpha-positive B cells are neural stem cells in the adult SVZ that form glioma-like growths in response to increased PDGF signaling. Neuron 51:187-199.

Johansson CB, Momma S, Clarke DL, Risling M, Lendahl U, Frisén J (1999) Identification of a neural stem cell in the adult mammalian central nervous system. Cell 96:25-34.

Kitamoto T, Hanaoka K (2010) Notch3 null mutation in mice causes muscle hyperplasia by repetitive muscle regeneration. Stem Cells 28:2205-2216.

Kohwi M, Osumi N, Rubenstein JL, Alvarez-Buylla A (2005) Pax6 is re- 
quired for making specific subpopulations of granule and periglomerular neurons in the olfactory bulb. J Neurosci 25:6997-7003.

Kohwi M, Petryniak MA, Long JE, Ekker M, Obata K, Yanagawa Y, Rubenstein JL, Alvarez-Buylla A (2007) A subpopulation of olfactory bulb GABAergic interneurons is derived from Emx1- and Dlx5/6-expressing progenitors. J Neurosci 27:6878-6891.

Kuhn HG, Winkler J, Kempermann G, Thal LJ, Gage FH (1997) Epidermal growth factor and fibroblast growth factor-2 have different effects on neural progenitors in the adult rat brain. J Neurosci 17:5820-5829.

Louvi A, Artavanis-Tsakonas S (2006) Notch signalling in vertebrate neural development. Nat Rev Neurosci 7:93-102.

Lugert S, Basak O, Knuckles P, Haussler U, Fabel K, Götz M, Haas CA, Kempermann G, Taylor V, Giachino C (2010) Quiescent and active hippocampal neural stem cells with distinct morphologies respond selectively to physiological and pathological stimuli and aging. Cell Stem Cell 6:445-456.

LütolfS, Radtke F, Aguet M, Suter U, Taylor V (2002) Notch1 is required for neuronal and glial differentiation in the cerebellum. Development 129:373-385.

Meletis K, Barnabé-Heider F, Carlén M, Evergren E, Tomilin N, Shupliakov O, Frisén J (2008) Spinal cord injury reveals multilineage differentiation of ependymal cells. PLoS Biol 6:e182.

Merkle FT, Mirzadeh Z, Alvarez-Buylla A (2007) Mosaic organization of neural stem cells in the adult brain. Science 317:381-384.

Mirzadeh Z, Merkle FT, Soriano-Navarro M, Garcia-Verdugo JM, AlvarezBuylla A (2008) Neural stem cells confer unique pinwheel architecture to the ventricular surface in neurogenic regions of the adult brain. Cell Stem Cell 3:265-278.

Mizutani K, Yoon K, Dang L, Tokunaga A, Gaiano N (2007) Differential Notch signalling distinguishes neural stem cells from intermediate progenitors. Nature 449:351-355.

Molofsky AV, Slutsky SG, Joseph NM, He S, Pardal R, Krishnamurthy J, Sharpless NE, Morrison SJ (2006) Increasing p16INK4a expression decreases forebrain progenitors and neurogenesis during ageing. Nature 443:448-452.

Morshead CM, Reynolds BA, Craig CG, McBurney MW, Staines WA, Morassutti D, Weiss S, van der Kooy D (1994) Neural stem cells in the adult mammalian forebrain: a relatively quiescent subpopulation of subependymal cells. Neuron 13:1071-12082.
Morshead CM, Garcia AD, Sofroniew MV, van Der Kooy D (2003) The ablation of glial fibrillary acidic protein-positive cells from the adult central nervous system results in the loss of forebrain neural stem cells but not retinal stem cells. Eur J Neurosci 18:76-84.

Mourikis P, Sambasivan R, Castel D, Rocheteau P, Bizzarro V, Tajbakhsh S (2012) A critical requirement for notch signaling in maintenance of the quiescent skeletal muscle stem cell state. Stem Cells 30:243-252.

Mumm JS, Kopan R (2000) Notch signaling: from the outside in. Dev Biol 228:151-165.

Nyfeler Y, Kirch RD, Mantei N, Leone DP, Radtke F, Suter U, Taylor V (2005) Jagged 1 signals in the postnatal subventricular zone are required for neural stem cell self-renewal. EMBO J 24:3504-3515.

Parras CM, Galli R, Britz O, Soares S, Galichet C, Battiste J, Johnson JE, Nakafuku M, Vescovi A, Guillemot F (2004) Mash1 specifies neurons and oligodendrocytes in the postnatal brain. EMBO J 23:4495-4505.

Pastrana E, Cheng LC, Doetsch F (2009) Simultaneous prospective purification of adult subventricular zone neural stem cells and their progeny. Proc Natl Acad Sci U S A 106:6387-6392.

Ramírez-Castillejo C, Sánchez-Sánchez F, Andreu-Agulló C, Ferrón SR, Aroca-Aguilar JD, Sánchez P, Mira H, Escribano J, Fariñas I (2006) Pigment epithelium-derived factor is a niche signal for neural stem cell renewal. Nat Neurosci 9:331-339.

Reynolds BA, Weiss S (1992) Generation of neurons and astrocytes from isolated cells of the adult mammalian central nervous system. Science 255:1707-1710.

Soriano P (1999) Generalized lacZ expression with the ROSA26 Cre reporter strain. Nat Genet 21:70-71.

Stump G, Durrer A, Klein AL, LütolfS, Suter U, Taylor V (2002) Notch1 and its ligands delta-like and Jagged are expressed and active in distinct cell populations in the postnatal mouse brain. Mech Dev 114:153-159.

Yoon K, Gaiano N (2005) Notch signaling in the mammalian central nervous system: insights from mouse mutants. Nat Neurosci 8:709-715.

Young KM, Fogarty M, Kessaris N, Richardson WD (2007a) Subventricular zone stem cells are heterogeneous with respect to their embryonic origins and neurogenic fates in the adult olfactory bulb. J Neurosci 27:8286-8296.

Young KM, Merson TD, Sotthibundhu A, Coulson EJ, Bartlett PF (2007b) p75 neurotrophin receptor expression defines a population of BDNFresponsive neurogenic precursor cells. J Neurosci 27:5146-5155. 